\title{
In memoriam Gret Nicole-Gisler
}

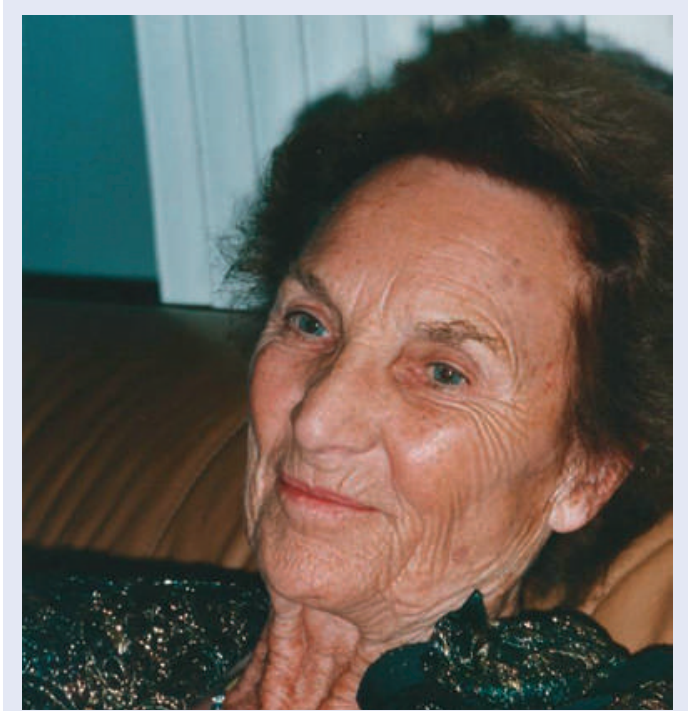

Dr. med. Gret Nicole-Gisler (20.7.1913-23.6.2012)

Am 23.6.2012 verstarb in Basel Frau Dr. med. Gret Nicole-Gisler, kurz vor ihrem 99. Geburtstag. Ihr Leben war bis in die letzten Tage erfüllt von aktiv erlebter Kunst und Kultur, Leidenschaft für Musik und Literatur und herzlicher Gastfreundschaft.

Das Leben von Gret Nicole-Gisler umspannt ein Spektrum von Begabungen und Fähigkeiten: geboren 1913 und aufgewachsen in Rorschach und St. Gallen, ergriff sie - nach einer aus gesundheitlichen Gründen abgebrochenen Ausbildung in Gesang - das Studium der Medizin, das sie nach Wien, Genf und Basel führte.

Bahnbrechend in der damaligen Zeit war ihre Ausbildung zur Chirurgin. Während des 2. Weltkrie- ges leitete sie während 2 Jahren die Chirurgische Abteilung des Kinderspitals Basel. Nach ihrer Verheiratung mit dem Chirurgen Prof. Robert Nicole verliess sie ihre leitende Stelle und setzte ihre ganze Energie in den Aufbau einer modernen Schule für Säuglingsschwestern am Bethesdaspital ein. Später eröffnete sie eine chirurgische Praxis an der Socinstrasse und operierte an verschiedenen Basler Spitälern. Sie war eine äusserst erfolgreiche, von ihren Patienten hoch geschätzte Chirurgin, beherrschte sowohl die Kunst des scharfen Messers als auch die umfassende, ärztliche Betreuung ihrer Patienten. Psychologisches Verständnis und die eigene, komplexe Lebenserfahrung befähigten sie zu engagierter Betrachtung und distanzierter Beurteilung.

Gret Nicole beeindruckte durch Bestimmtheit, Offenheit für andere Menschen und Probleme, aber auch Verschwiegenheit. Sie lebte in einem grossen Freundeskreis, den sie mit ihrem vifen Geist bereicherte, manchmal hinterfragte, aber immer stützte. Familie und Freunde verlieren mit ihrem Hinschied einen Menschen von seltener Ausstrahlung, Sensibilität, scharfer Beobachtungsgabe und Mut zu Aktion und eindeutigem Urteil, einen anregenden Gesprächspartner und weisen Ratgeber.

Familie und Freunde gedenken Gret Nicole-Gisler in Respekt für ihre ärztliche Leistung und in Dankbarkeit für das über Jahrzehnte Empfangene. Gret Nicole bleibt uns ein Vorbild durch ihre vitale Persönlichkeit, ihren Verantwortungssinn und Gestaltungswillen, aber auch ihr Arbeitsethos, ihre Gradlinigkeit und persönliche Bescheidenheit. Mit ihrer Person gab sie uns Richtung und ermunterte zu Verantwortung und Aktivität.

Dr. med. Dieter Scholer, Bottmingen 